\title{
Ethics, Values, Virtues, and Character Strengths in Mindfulness-Based Interventions: a Psychological Science Perspective
}

\author{
Ruth Baer $^{1}$
}

Published online: 21 June 2015

(C) Springer Science+Business Media New York 2015

\begin{abstract}
This paper comments on an article by Monteiro, Musten, and Compson (Mindfulness 6: 1-13, 2015) and a series of replies that explored the issue of ethics training for participants in contemporary mindfulness-based interventions (MBIs). The perceived need for explicit ethical training stems from concerns about potentially harmful or misguided applications of secular MBIs, particularly in settings whose activities may be inconsistent with the ethics of the Buddhist traditions from which mindfulness training originates. Much of the discussion in the target article and replies focused on whether ethical foundations of mindfulness in MBIs should remain implicit or should be taught from a Buddhist perspective. The present commentary argues that psychological science provides well developed alternatives for researchers and clinicians interested in secular approaches to ethics-related issues in MBIs. The experimental psychology literature provides a strong foundation for working with personally meaningful, prosocial values in MBIs. Positive psychology provides a complementary perspective on moral virtues and character strengths that have been widely recognized across cultures. Organizational psychology and related disciplines provide empirically based perspectives on the ethical implications of mindfulness training in the workplace. An approach to ethical issues in MBIs that is firmly grounded in psychological science and suitable for secular settings is recommended.
\end{abstract}

Ruth Baer

rbaer@email.uky.edu

1 Department of Psychology, University of Kentucky, 115 Kastle Hall, Lexington, KY 40506-0044, USA
Keywords Mindfulness-based interventions - Ethics · Values $\cdot$ Positive psychology $\cdot$ Virtues and character strengths $\cdot$ Worksite mindfulness training

\section{Introduction}

The relationship between Buddhist conceptions of mindfulness and the contemporary psychological perspectives of mindfulness-based interventions (MBIs) has been extensively discussed (Williams and Kabat-Zinn 2013). In a recent review, Monteiro et al. (2015) described several criticisms of secular MBIs from the Buddhist perspective; the most serious of these was the lack of explicit ethics training for participants. Particular concern was expressed about workplace applications of mindfulness training where corporate expectations might not be consistent with traditional Buddhist ethics. Replies to Monteiro et al. offered a range of perspectives on this topic; the discussion focused largely on whether ethical foundations of mindfulness should remain implicit or should be taught from a Buddhist perspective. Much of the psychological literature on evidence-based ways of working with ethics-related issues in MBIs was not addressed.

The present commentary argues that psychological science provides well-developed alternatives to both Buddhist-based and implicit approaches for researchers and clinicians interested in secular perspectives on ethical issues in MBIs. The experimental psychology literature provides a strong foundation for explicit work with personally meaningful prosocial values in MBIs. Positive psychology provides a complementary perspective on moral virtues and character strengths that have been widely recognized across cultures. Organizational psychology and related disciplines provide empirically based perspectives on the ethical implications of mindfulness training in 
the workplace. Following an overview and discussion of these bodies of literature, I argue for a psychological science-based approach that is theoretically sound, empirically supported, and suitable for contemporary secular settings.

\section{Ethical Training in MBIs}

Monteiro et al. and several of the replies noted that in Buddhist traditions, mindfulness training is accompanied by explicit instruction in ethical conduct as part of the eightfold path to the cessation of suffering. This foundational Buddhist teaching includes two components within the domain of wisdom (right view, right intention), three devoted to ethical behavior (right speech, right action, right livelihood), and three devoted to mental or meditative development (right effort, right concentration, right mindfulness). The term right signifies that each element of the path leads to reduced suffering for self or others (Amaro 2015; Monteiro et al. 2015); for example, right livelihood means earning one's living in a way that is benevolent and causes no harm. Ethical behavior in Buddhist traditions is further described in the five precepts: to refrain from killing, stealing, lying, sexual misconduct, and misuse of intoxicants. These are sometimes expressed in more general terms (nonharming of living beings, nonharmful speech, etc.) and are understood not as commandments from a higher authority but rather as pragmatic ways of facilitating one's own awakening and the well-being of others (Amaro 2015).

According to some authors, the absence of explicitly taught ethics in secular MBIs is a source of concern because it could lead to the development of wrong mindfulness (Monteiro et al. 2015) or mindfulness used for harmful purposes. A commonly cited example is the provision of mindfulness training within businesses or corporations whose profit-driven activities may lead to degradation of the environment, harm to the economy, or mistreatment of their employees. Some authors have suggested that the availability of worksite mindfulness training unfairly implies that employees are solely responsible for their own stress levels and disregards sources of stress within the organization. It has also been suggested that without clear and explicit ethical foundations, the practice of nonjudgmental acceptance could promote acquiescence with unethical business practices and passive tolerance of oppressive working conditions (Purser 2015). To address these concerns, Monteiro et al. suggested that explicit teaching of Buddhistconceptualized ethics in secular MBIs should be explored. In response, some of the commentaries agreed while others argued that ethics training is already implicit in secular MBIs and that explicit ethical training is unnecessary or could be problematic.

\section{Implicit Ethics in MBIs}

Three points are commonly made in support of the argument that an ethical foundation is implicit in MBIs. First, many providers of MBIs (psychologists, physicians, social workers) are bound by codes of professional ethics that require them to do no harm and to work from a standpoint of beneficence and respect. The code of conduct for psychologists notes that ethical practice requires "a personal commitment and lifelong effort to act ethically; to encourage ethical behavior by students, supervisees, employees and colleagues; and to consult with others concerning ethical problems" (APA 2010). According to Kabat-Zinn (2011), candid communication between teachers of mindfulness-based stress reduction (MBSR) assists colleagues in identifying and challenging their own and others' behavior that might inadvertently cause harm. Linehan (1993) formalized this principle by making a therapists' consultation group an essential component of dialectical behavior therapy (DBT), a well-supported mindfulness-based treatment for borderline personality disorder. The consultation group helps therapists manage the stress of working with potentially suicidal clients, conduct the therapy in DBT-consistent ways, and maintain an ethical stance.

Second, many definitions in the contemporary psychological literature describe mindfulness as having two elements: what one does when practicing (i.e., paying attention to present-moment experiences) and how one does it (the nature or qualities of the attention). Examples are shown in Table 1 and suggest that mindful awareness is generally agreed to be nonjudgmental, open, accepting, curious, compassionate, and kind. In a commentary on Monteiro et al., Grossman (2015) described these characteristics as virtuous and suggested that the practice of mindfulness cultivates an inherently ethical stance toward self and others.

Finally, Kabat-Zinn (2005) and Segal et al. (2013) noted that MBSR and MBCT are offered with a spirit of compassion and kindness. Teachers' embodiment of these qualities, as well as frequent reminders in the meditation instructions to be nonjudgmental, open, and curious, is believed to help participants learn to treat themselves with more warmth and friendliness. Several studies have shown increases in selfcompassion following MBSR and MBCT (Keng et al. 2012; Kuyken et al. 2010). A few have shown increased empathy for others following MBSR (Birnie et al. 2010; Shapiro et al. 1998). Using a behavioral task to avoid the pitfalls of selfreport, Condon et al. (2013) found that participants who had just completed an 8-week mindfulness course were three times more likely than a control group to offer their chair in a waiting room to a confederate struggling with crutches. This study compared two mindfulness training protocols; one included compassion meditation, the other did not. Participants in these two conditions were equally likely to offer help, suggesting that explicit instruction in compassion-based practices 
Table 1 Contemporary psychological descriptions of mindfulness: what and how

\begin{tabular}{|c|c|c|}
\hline Author(s) & What & How \\
\hline Kabat-Zinn $(1994,2003)$ & $\begin{array}{l}\text { Paying attention, or the awareness that } \\
\text { arises through paying attention... }\end{array}$ & $\begin{array}{l}\text {...on purpose, in the present moment, and nonjudgmentally; } \\
\text {... with an affectionate, compassionate quality, a sense of } \\
\text { openhearted friendly presence and interest }\end{array}$ \\
\hline Marlatt and Kristeller (1999) & $\begin{array}{l}\text { Bringing one's complete attention to } \\
\text { present experiences... }\end{array}$ & $\begin{array}{l}\text {...on a moment-to-moment basis, with an attitude of } \\
\text { acceptance and loving kindness }\end{array}$ \\
\hline Bishop et al. (2004) & $\begin{array}{l}\text { Self-regulation of attention so that is } \\
\text { it maintained on immediate experience... }\end{array}$ & $\begin{array}{l}\text {...with an orientation characterized by curiosity, openness, } \\
\text { and acceptance }\end{array}$ \\
\hline Germer et al. (2005) & Awareness of present experience... & $\begin{array}{l}\text {... with acceptance: an extension of nonjudgment that } \\
\text { adds a measure of kindness or friendliness }\end{array}$ \\
\hline Linehan (2015) & $\begin{array}{l}\text { The act of focusing the mind in the } \\
\text { present moment... }\end{array}$ & $\begin{array}{l}\text {... without judgment or attachment, with openness to } \\
\text { the fluidity of each moment }\end{array}$ \\
\hline
\end{tabular}

may not be necessary to cultivate increases in kindness toward others through mindfulness training.

In summary, proponents of the implicit approach to ethics in MBIs note that the entire enterprise is suffused with compassion and ethical awareness. Teachers are bound by codes of ethical conduct, mindfulness itself is inherently ethical, and the practice of mindfulness cultivates kindness and compassion toward self and others.

\section{Teaching Buddhist-Based Ethics in MBIs}

Monteiro et al. and several of the replies argued that the implicit approach to ethical training in secular MBIs may not be sufficient to prevent ethically problematic applications of mindfulness training and suggested that explicit teaching of Buddhist-based ethics could be helpful. Most of these authors offered little specificity about how such training might be conducted, but several pointed to examples in the published literature. These include spiritual self-schema therapy (Avants and Margolin 2004), meditation awareness training (MAT; Shonin et al. 2014a), mindfulness-integrated cognitive behavioral therapy (MiCBT; Cayoun 2011), and mindfulness-based symptom management (MBSM; Monteiro and Musten 2013; Monteiro et al. 2010).

Spiritual self-schema therapy for addictive and HIV risk behavior is an 8-week group program that integrates a cognitive model of self with "a nonsectarian Buddhist framework suitable for people of all faiths" (Avants et al. 2005, p. 167). Participants typically have been engaging in high-risk sexual behavior (e.g., prostitution), stealing and lying (to acquire drugs or conceal drug-related activities), and harmful ways of earning money (drug dealing). The intervention provides explicit instruction in the five ethical precepts and the eightfold path, including right livelihood, right speech, and right action. The primary goal is to help participants develop a spiritual self-schema that is incompatible with HIV risk behaviors. Lapses are characterized as reactivations of addict self-schemas rather than moral failings. Participants are encouraged to view their behavior "with compassion, without judgment, and with the goal of targeting and eliminating the addict self-schema, rather than targeting and punishing themselves" (p. 272). Several studies of this treatment have reported reductions in HIV-risk behavior and increases in qualities such as generosity, morality, renunciation, and wisdom (Margolin et al. 2006; Margolin et al. 2007).

Meditation awareness training (MAT; Shonin et al. 2014a) is an 8-week intervention delivered in group or individual format. It is described as secular yet designed to provide a more traditional and comprehensive approach to meditation than is found in MBSR and MBCT. Mindfulness is an integral component of the program but not the exclusive focus. MAT also includes methods that cultivate citizenship, ethical and compassionate awareness, generosity, patience, and insight into Buddhist conceptions of impermanence and nonself. Weekly sessions are led by experienced meditators and include a didactic component, group discussion, and a guided meditation or mindfulness exercise. Several studies support the efficacy of MAT for improving psychological well-being in a variety of populations as well as job satisfaction and performance in worksite settings (Shonin et al. 2014b, c, d; Van Gordon et al. 2014).

Mindfulness-integrated cognitive behavioral therapy (MiCBT; Cayoun 2011) is an 8-12-week program designed to address a broad range of psychological disorders and general stress conditions. It integrates mindfulness meditation with exposure procedures, interpersonal skills training, and exercises for developing empathy, compassion, and ethical behavior. The ethical training component includes explicit discussion of the five precepts, which participants are encouraged to apply in daily life using behavioral experiments. For example, they might attempt to refrain from killing insects or telling lies for a week. If they find it necessary to engage in these behaviors, they are encouraged to be fully aware of all associated sensations. No published studies have evaluated the efficacy of MiCBT.

Mindfulness-based symptom management (Monteiro and Musten 2013) is an 8-week group program for people with 
mood-, stress-, and pain-related conditions. It combines elements of MBSR, MBCT, and Buddhist philosophy and includes five skillful habits based on the precepts of Buddhist ethics in substantially adapted form. For example, refraining from killing is relabeled as respect for mortality; the associated habits include noting sensations and negative thoughts, noticing how negative emotions lead to physical problems, and physical exercise. The precept about intoxicants is relabeled as mindful consumption; recommendations include noting the sensations, thoughts, and emotional effects of eating and satiation, taking time for lunch, and limiting snacks. Many of these strategies are included in MBIs that do not claim to have an explicit ethical component; thus, the Buddhist influence seems largely implicit. No published studies have evaluated the efficacy of this program.

\section{Values}

In a commentary on Monteiro et al., Davis (2015) noted that Buddhism is not the only source of guidelines about ethical behavior and suggested that teaching Buddhist-based ethics to people who do not identify as Buddhists could be problematic. Instead, he recommended helping participants clarify the values they already hold and strengthen their resolve to embody them. Similarly, Greenberg and Mitra (2015) pointed to the CARE for Teachers program (Cultivating Awareness and Resilience in Education; Jennings et al. 2011, 2013) which encourages participants to develop a statement of the values that motivated them to become teachers and to use these values to guide their behavior. Other MBIs, particularly acceptance and commitment therapy (ACT; Hayes et al. 1999, 2012), also include working with self-chosen values as a central treatment strategy.

\section{Values in ACT}

ACT is based on the psychological flexibility model: a comprehensive theory of human functioning that integrates mindfulness- and acceptance-based psychological processes with personally chosen values and values-consistent behavior (known as committed action). The mindfulness and acceptance processes in ACT are similar to those described in other MBIs and include flexible attention to the present moment, acceptance of present-moment experiences, defusion from thoughts (similar to decentering in MBCT), and a transcendent sense of self (recognition that thoughts and feelings are transitory events that do not define the person who is experiencing them). In ACT, values are seen as essential to good psychological health because they intrinsically motivate behavior that leads to a deep sense of meaning, vitality, and engagement. The ultimate goal of ACT is to help clients develop lives that feel rich and satisfying - though not painless or easy - by the clients' own standards (Hayes et al. 2012).

When helping clients to identify their values, ACT therapists typically encourage the exploration of several domains that are important in many people's lives. Domains are not prescribed, but rather are suggested to help clients focus on what may be most important to them. Commonly discussed domains include relationships (with family or friends), work (career, education, or running a household), community involvement (working for worthy causes, participating in community activities), spirituality (church involvement, communing with nature, or other practices identified by the client), and self-development (learning new skills, taking care of one's health, engaging in satisfying leisure activities). The importance of choosing one's own values, rather than those imposed by authority figures or societal norms, is emphasized.

Discussion of values in ACT also includes qualities or characteristics that clients would like to embody in the domains that are most important to them. In the work domain, clients may aspire to be creative, competent, or productive. In the relationship domain, they may wish to be loving, kind, or supportive. Values are distinguished from goals, in that goals can be completed or achieved (learn a new software program, teach coworkers to use it), whereas the underlying values (to be competent and helpful) continue over the longer term. Upon completion of specific goals, other ways to be competent and helpful will present themselves. A client who stops working may continue to value competence and helpfulness in other settings.

Behaving in accordance with values can be stressful and difficult. Unpleasant thoughts and emotions may arise, and these often present obstacles to committed action. Mindfulness and acceptance are conceptualized as ways to help clients work constructively with emotional obstacles to values-consistent behavior. For example, a person who values helpfulness at work but is anxious about speaking in groups might practice contributing to discussions with mindful acceptance of the unpleasant sensations (racing heart, sweating), rather than keeping quiet in meetings to avoid the stress of speaking up. The goal of ACT is not to decrease anxiety in meetings, though this may occur with consistent practice. Rather, the goal is to help the client develop a life that feels satisfying and meaningful, even when it is distressing or painful.

ACT has developed several tools to help clients explore their values. The Valued Living Questionnaire (Wilson et al. 2010), which is often used as a structured interview (Wilson and DuFrene 2008), asks clients to consider 12 potentially valued domains: marriage, parenting, other family, friends, work, education, recreation, spirituality, community life, physical self-care (diet, exercise, sleep), the environment, 
and aesthetics (art, literature, music, beauty). Clients are urged to remember that not everyone values all of the domains; for example, some prefer not to marry or raise children, others may have little interest in community activities or spirituality. Discussion centers on the self-rated importance of each area, the client's actions in each area, and satisfaction with their level of action. The intention is to work toward greater consistency between self-rated importance of particular domains and satisfaction with action in those domains. Clients who discover that they have been focusing on areas of low priority while neglecting domains they identify as important can be helped to redirect their energies in more satisfying ways. Mindful compassion provides a helpful way of relating to the pain and regret associated with realizing that one's priorities may have been misplaced.

ACT also uses experiential exercises to help clients identify important values. Clients may be asked to write a brief epitaph for their own future tombstone that captures how they would like to be remembered; e.g., "He participated in life and helped his fellow human beings" (Hayes et al. 2012, p. 306). Alternatively, they might write a short speech they would like someone to give at a birthday party in their honor; for example, "John always puts the needs of his children first, guiding them with love, patience, and respect" or "Through her tireless volunteer work, Camille has helped to make our world a safer and cleaner place for all living beings" (Fleming and Kocovski 2013, p. 32). Such exercises are followed by discussion of behaviors consistent with these values, especially behavioral changes needed to address values-behavior discrepancies. Mindfulness skills that may be helpful in working with barriers to committed action, such as pessimistic or selfcritical thoughts ("This will never work," "I've wasted too much time"), and negative emotions (anxiety, sadness), are also practiced.

Many studies have shown that ACT leads to significant increases in self-reported psychological flexibility, defined as the ability to fully contact the present moment and behave in values-consistent ways in the presence of difficult thoughts and feelings (Hayes et al. 2006; Ruiz 2010). Treatment outcome studies have not examined the effects of values work independently of the other components of ACT; however, laboratory studies suggest that even brief consideration of personal values leads to reliable changes in behavior. For example, in a study of pain tolerance using the cold-pressor task (immersing a hand in very cold water), Branstetter-Rost et al. (2009) asked one group to imagine tolerating the pain for the sake of a highly ranked personal value (e.g., swimming in icy water to rescue a loved one), whereas a second group was coached in how to practice mindful acceptance of the pain with no reference to personal values, and a third group received no instructions for tolerating the pain. All groups rated the cold water as equally painful, but the values group tolerated the pain for much longer than the acceptance and no-instructions groups $(156,69$, and $36 \mathrm{~s}$, respectively, $p<.001)$. Several ACT-based laboratory studies have reported similar findings (Levin et al. 2012).

\section{Values in Self-Affirmation Theory}

ACT researchers often cite a body of values-based studies conducted in the context of self-affirmation theory (Steele 1999). This theory posits that affirmation of personal values protects against a variety of stressors by expanding participants' views of themselves and their resources and facilitating perspective on what is most important. Participants are asked to write for a few minutes about a highly ranked value; most write about relationships with family or friends, religious faith, or kindness. Significant changes in subsequent behavior are consistently observed (Cohen and Sherman 2014). Smokers who wrote about their personal values showed greater willingness than controls to acknowledge the health risks of smoking (Crocker et al. 2008). Sexually active adults who wrote about their values were more likely than controls to purchase condoms after viewing an educational video about AIDS (Sherman et al. 2000). First-generation college students who wrote about their values showed improved grades in a biology course and greater likelihood of enrolling in a subsequent course (Harackiewicz et al. 2014). Physiological effects also have been documented. Creswell et al. (2005) reported that students who focused on a highly ranked value showed lower cortisol responses to a laboratory stressor than a control group. Legault et al. (2012) found that students who wrote about an important value showed greater electrophysiological evidence of error monitoring in the brain and fewer performance errors on a laboratory task.

\section{Values in Other MBIs}

Working with values has been integrated into other empirically supported MBIs in a variety of ways. Mindfulness-based eating awareness training (Kristeller et al. 2014) helps participants consider the time and energy they spend thinking obsessively about food, eating, and weight, rather than work, school, family, or friends, and encourages them to increase their involvement in these valued activities. Mindfulnessbased relapse prevention (Bowen et al. 2011) includes discussion of reasons to stay sober, which participants write on cards to carry with them as reminders to avoid relapses. These reasons typically reflect important values, such as working responsibly at a job, caring for a child, or relating to a spouse. Acceptance-based behavior therapy (Roemer et al. 2008), which integrates elements of ACT, MBCT, and DBT, uses writing exercises to help clients explore what they value in a variety of domains (work, school, relationships, household management, community 
involvement, self-care); it also includes goal setting and behavior change strategies for increasing values-consistent action in daily life.

During a sitting meditation in the final session of MBCT, participants are asked to contemplate something they value that provides a reason to maintain their mindfulness practice after the group has ended. They write the values that came to mind (such as caring for themselves or being more available to their children) on cards to keep with them. Finally, DBT (Linehan 2015) includes exploration of values as part of building a life that feels satisfying and meaningful. Although potential values are suggested to help clients consider possibilities (e.g., healthy relationships, productive work, contributing to the community), clients are strongly encouraged to identify values that are truly their own.

\section{The Importance of Self-Chosen Values}

Studies of self-affirmation typically ask the experimental group to write about their most important value and the control group to write about a low-ranked value. The consistent superiority of experimental over control groups in beneficial outcomes suggests that thinking about one's own highly ranked values is important. This finding is consistent with theories of optimal human functioning that emphasize the role of autonomy. Self-determination theory (Ryan and Deci 2000) identifies autonomy as one of three basic needs (along with competence and relatedness) that are essential for psychological health and life satisfaction. Ryff's (1989) comprehensive theory of psychological well-being also includes autonomy as a critical element of healthy functioning. Studies of the self-concordance model (Sheldon and Elliott 1999) show that pursuit of goals that reflect authentic personal interests and values is associated with increased goal attainment and higher overall well-being (Gillet et al. 2014; Sheldon 2002).

ACT experts note that when clients are encouraged to think autonomously about their deepest aspirations, they almost invariably choose prosocial values, such as meaningful work, loving relationships, and contributions to a community (Hayes et al. 2012). When this does not happen, e.g., a client says that he values making a lot of money, further discussion about why money is important is likely to reveal prosocial underlying values, such as providing security or opportunities for one's family. If values appear to conflict (e.g., providing financial security for the family versus spending time with them), discussion focuses on finding patterns of committed action that serve both values and provide greater overall satisfaction with life.

The prevailing tendency to identify prosocial values is believed to reflect universal human requirements for biological survival, social interaction, and the welfare of groups (Schwartz and Bilsky 1987, 1990). That is, individuals and societies are more likely to thrive if people take care of themselves, help each other, and work for the benefit of the group. Of course, these universal needs do not invariably prevent harmful behaviors. However, current psychological theories, research, and treatment methods consistently suggest that encouraging people to identify their own most deeply held values may promote adaptive and prosocial behaviors more effectively than adopting a list of values prescribed or suggested by others.

\section{The Virtues and Character Strengths of Positive Psychology}

In his commentary on Monteiro et al., Davis (2015) noted that cultures hold diverse views of the ethical qualities that human beings should cultivate. A strong foundation for ethical training in secular MBIs, therefore, requires discussion of "the very general ethical question of how it is best for a human being to be" (p. 46). It seems unlikely that any field of study can provide a universally acceptable answer to this question. However, psychological science has explored this critically important topic through the field of positive psychology, which studies optimal human functioning. The central tenet of positive psychology is that mental health is more than the absence of pathology or distress and that psychological science should include the study of how individuals and communities can flourish and thrive. A central concern of positive psychology is the understanding and cultivation of human virtues that define good character or "the domain of moral excellence" (Peterson and Seligman 2004, p. 8).

\section{Core Virtues}

To explore whether any human virtues have been universally recognized as exemplars of moral excellence, Peterson and Seligman (2004; see also Dahlsgaard et al. 2005) conducted a wide ranging review of historical and contemporary literatures and developed a framework for defining and classifying virtues and character strengths. Working with a large team of collaborators over a 3-year period, they studied spiritual and philosophical texts from ancient cultures that provide explicit discussion of the nature of human virtue and are recognized for their enduring influence on human civilization. These included the teachings of Confucius collected in the Analects; the virtues of Taoism described in the Tao Te Ching; the Buddhist virtues enumerated in the eightfold path, the five ethical precepts, and the four immeasurables; Hindu virtues described in the Bhagavadgita; Athenian virtues described by Plato in The Republic and Aristotle in the Nicomachean Ethics; Judeo-Christian virtues as described in the Ten Commandments, the two books of 
Proverbs, and Aquinas's Summa Theologiae; and Islamic virtues discussed by Alfarabi in the Selected Aphorisms. Many secondary sources and expert commentaries were consulted.

Although no two sets of virtues were identical, convergence across these diverse traditions suggested that six core virtues consistently recognized as necessary for good character could be identified: wisdom, courage, humanity, justice, temperance, and transcendence. In the Buddhist tradition, for example, wisdom is represented by right view and intention; justice by precepts to refrain from killing, stealing, and lying; humanity by these precepts and several of the immeasurables (compassion, kindness, sympathetic joy); temperance by precepts to refrain from misuse of intoxicants and sexual misconduct; and transcendence by the emphasis on overcoming the suffering of continual death and rebirth. In the Athenian tradition, Plato proposed four core virtues: wisdom, courage, self-restraint (temperance), and justice; Aristotle included these four and also discussed generosity, friendliness, and charitable acts (humanity). Transcendence was not named explicitly as a virtue but was judged to be implicit in many of Plato's and Aristotle's writings. Peterson and Seligman (2004) proposed that the capacities for these six virtues may be biologically based and may have evolved because they contribute to survival of the species.

\section{Character Strengths}

Peterson and Seligman (2004) also identified several character strengths through which each of the core virtues can be achieved or expressed. Character strengths are described as psychological processes or mechanisms that define the virtues. For example, humanity is expressed through love, kindness, and social intelligence; justice is expressed through citizenship, fairness, and leadership. As with the virtues, consistently recognized character strengths were identified through comprehensive literature reviews. In addition to the spiritual and philosophical texts just described, numerous other lists of character strengths from historical and contemporary sources were studied. These included William Bennett's Book of Virtues (1993: courage, perseverance, honesty, friendship, loyalty, compassion, self-discipline, faith), the Boy Scout Handbook (1998: bravery, trustworthiness, helpfulness, kindness, loyalty, thrift, courtesy, reverence), Benjamin Franklin's catalog of moral virtues (1790/1961: order, industry, sincerity, justice, humility, temperance), and Charlemagne's code of chivalry for the knights of the Holy Roman Empire (Turner 1880: kindness, forgiveness, mercy, humility, service; avoidance of stealing, perjury, and excess in eating and drinking).

After removing redundancies, characteristics were retained if they were morally valued and encouraged across cultures and potentially measurable. Table 2 shows the complete list of six virtues and 24 character strengths currently recognized within the context of positive psychology, subject to change with future work (Peterson and Park 2011).

\section{Assessment of Virtues and Character Strengths}

Most of the character strengths can be assessed using tools (primarily self-report instruments) available before the advent of positive psychology. Since then, researchers have developed the Values in Action Inventory of Strengths (VIA-IS; Park and Peterson 2006), a questionnaire that assesses all 24 of the strengths. The VIA-IS conceptualizes the strengths as individual differences that are reasonably stable and consistent across time and situations, though subject to change with experience and practice. Respondents complete the VIA-IS online and are provided with a list of their top five strengths (known as signature strengths) and a short description of what each strength means. A version of the VIA-IS for youth

Table 2 The six core virtues and their associated character strengths

\begin{tabular}{|c|c|}
\hline Virtues & Character strengths \\
\hline Wisdom & $\begin{array}{l}\text { Creativity (originality, ingenuity) } \\
\text { Curiosity (interest, novelty-seeking, } \\
\text { openness to experience) } \\
\text { Open-mindedness (judgment, } \\
\text { critical thinking) } \\
\text { Love of learning } \\
\text { Perspective }\end{array}$ \\
\hline Courage & $\begin{array}{l}\text { Bravery (valor) } \\
\text { Persistence (perseverance, industriousness) } \\
\text { Integrity (authenticity, honesty) } \\
\text { Zest (vitality, enthusiasm, vigor, energy) }\end{array}$ \\
\hline Humanity & $\begin{array}{l}\text { Love } \\
\text { Kindness (generosity, nurturance, care, } \\
\text { compassion, altruistic love) } \\
\text { Social intelligence (emotional intelligence, } \\
\quad \text { personal intelligence) }\end{array}$ \\
\hline Justice & $\begin{array}{l}\text { Citizenship (social responsibility, } \\
\quad \text { loyalty, teamwork) } \\
\text { Fairness } \\
\text { Leadership }\end{array}$ \\
\hline Temperance & $\begin{array}{l}\text { Forgiveness (mercy) } \\
\text { Humility (modesty) } \\
\text { Prudence } \\
\text { Self-regulation (self-control) }\end{array}$ \\
\hline Transcendence & $\begin{array}{l}\text { Appreciation of beauty and excellence } \\
\text { (awe, wonder, elevation) } \\
\text { Gratitude } \\
\text { Hope (optimism, future mindedness, } \\
\text { future orientation) } \\
\text { Humor (playfulness) } \\
\text { Spirituality (religiousness, faith, purpose) }\end{array}$ \\
\hline
\end{tabular}


aged 10-17 years is available, as is a structured interview (Peterson et al. 2005).

The online version for adults has been completed by over three million people in most countries around the world (Niemiec and Lissing 2015). All scales of the VIA-IS have shown satisfactory internal consistency, test-retest reliability, and convergent relationships with reports by others (see Niemiec 2013, for a summary). Interesting correlates have been reported. For example, life satisfaction has been consistently associated with hope, zest, gratitude, curiosity, and love (Park et al. 2004). Recovery from physical illness is associated with bravery, kindness, and humor, coping with psychological disorders with appreciation of beauty and love of learning (Peterson et al. 2006). Grade point average in college students is most strongly related to persistence, open-mindedness, love of learning, and self-regulation (Lounsbury et al. 2009). Only two of the 24 scales (prudence and spirituality) have been shown to be correlated with measures of socially desirable responding (Niemiec 2013).

\section{Interventions that Cultivate Character Strengths}

A commonly used approach to intervention in positive psychology is to help participants use their signature strengths (identified by the VIA-IS) more frequently and in new ways. Examples include refraining from telling white lies (authenticity), speaking in support of an unpopular idea in a group discussion (bravery), doing anonymous favors for others (kindness), listening to others without interrupting (fairness), helping someone else feel at ease (social intelligence), volunteering with a charitable organization (teamwork), and numerous others (Peterson 2006). Studies have shown increases in happiness and decreases in depression for several months following such interventions (Seligman et al. 2005; Proyer et al. 2014).

Research also supports the efficacy of training programs for some of the strengths considered singly. Gratitude interventions improve psychological well-being and may foster prosocial behavior (McCullough et al. 2008; Emmons and Mishra 2011). Forgiveness interventions lead to increases in forgiveness and hope and decreases in depression and anxiety (Wade et al. 2014). Daily self-control exercises lead to increases in a general capacity for self-regulation (Baumeister et al. 2006). Creativity training programs produce significant increases in divergent thinking and problem solving (Scott et al. 2004). Loving-kindness and compassion meditation lead to increases in positive emotion and feelings of connection with others as well as decreases in negative emotion and stress (Hofmann et al. 2011). These meditation practices are closely related to mindfulness meditation and are often taught within the context of mindfulness training programs such as MBSR.

\section{Mindfulness Training and the Cultivation of Character Strengths}

The effects of MBIs on character strengths have not been comprehensively investigated; however, studies suggest that mindfulness training encourages curiosity, kindness, self-regulation, vitality, and spirituality, and that dispositional mindfulness is related to many of the strengths (for reviews, see Baer and Lykins 2011; Niemiec 2014). The only intervention explicitly designed to cultivate both mindfulness and character strengths is mindfulness-based strengths practice (MBSP; Niemiec 2014), a newly developed 8-week group program. MBSP has roots in MBSR and MBCT and uses several of the same exercises (body scan, sitting meditation, mindful walking, mindful eating, and the breathing space) to teach mindful awareness of present-moment experiences. MBSP also teaches participants to recognize and understand their own character strengths. Mindfulness skills and character strengths then are used in combination to enhance well-being and quality of life. Mindfulness facilitates the recognition and wise use of strengths. Conversely, when it is difficult to practice mindfulness, strengths such as persistence or curiosity can be applied.

Some participants in MBSP choose to work primarily with their signature strengths, others with their lower ranked ones. The concept of the golden mean - based on Aristotle's writings and similar to the Buddhist conception of the middle way-is used to encourage a balanced, mindful use of strengths attuned to context. For example, strengths can be underused or overused. Too little bravery is cowardice, too much may be reckless; too little curiosity is apathy, too much could be perceived as nosiness. Moreover, different situations call for different strengths, or combinations of strengths. When completing income tax forms, persistence, prudence, and integrity may be more adaptive than creativity and humor.

No peer-reviewed trials of MBSP have been published. A pilot study (described in Niemiec 2011) showed substantial improvements in flourishing, engagement in absorbing activities, and use of signature strengths in daily life for participants in MBSP. In an unpublished study, Briscoe (2014) reported similar changes. Ongoing trials are examining the efficacy of MBSP for a variety of settings and populations.

\section{Mindfulness Training in the Workplace}

Worksite stress reduction programs have been available since well before the widespread use of secular MBIs. An early review (Murphy 1984) noted that corporate expectations for such programs typically include improvements in productivity, job satisfaction, and morale, as well as reduced medical and disability costs, absenteeism, and turnover. The content of such programs typically reflects contemporaneous psychological research on treatment methods. Relaxation training 
became a staple of worksite stress management in the 1970s; cognitive restructuring was incorporated in the $1980 \mathrm{~s}$ (Flaxman and Bond 2006). It is not surprising that mindfulness-based methods are popular now.

Experts in worksite stress reduction have long recognized the importance of both individual-directed and organization-directed interventions (Ganster et al. 1982). The former teach stress management to workers, whereas the latter focus on modifying workplaces to be less stressful. Murphy (1984) acknowledged the potential injustice of offering stress management to employees while making no effort to improve poorly designed work environments but concluded that worker-directed programs can have significant benefits and "should not be discarded simply because they do not attempt to reduce or eliminate objective stressors in the work environment" (p. 13). Bond (2004) noted that even in well-designed work environments, jobrelated stressors such as difficult customers and seasonal deadlines cannot be entirely eliminated; neither can external stressors that influence work performance (e.g., family discord). Bond (2004) argued for a comprehensive approach that includes both healthy working conditions (reasonable demands, supportive supervisors) and training programs for employees wishing to learn stress management skills.

Several MBIs have been studied as worksite interventions. ACT has been shown to lead to improvements in employees' mental health, work performance, and propensity to innovate, as well as reductions in burnout and illness-related absences. Mediation analyses consistently show that these effects can be attributed to increases in psychological flexibility, defined as present-moment awareness combined with values-consistent behavior (Flaxman and Bond 2010; Flaxman et al. 2013). MBSR has been shown to reduce stress and burnout and improve life satisfaction in health care professionals (Irving et al. 2009). Several case studies of workplace MBSP programs reported improvements in employees' ability to resolve disputes, reduce interpersonal tension, and manage stress (Niemiec and Lissing 2015). Wolever et al. (2012) developed a 12-week mindfulness-based program designed specifically for workplace delivery and reported significant improvements in stress, sleep quality, and autonomic balance in a large group of employees of an insurance company.

When organizations (or individuals within them) are engaging in harmful or unethical practices, employees are believed to be the most effective source of corrective action (Miceli and Near 2005). Through a process known as whistle-blowing, employees who report illegal or unethical activities can have a significant impact on organizational behavior (Vadera et al. 2009). Miceli et al. (2012) noted that most employees who observe wrongdoing do not report it but that those who do are more likely to have a proactive personality style characterized by the tendency to take action to influence their environment. The Proactive Personality Scale (Bateman and Crant 1993) measures this style with items such as, "I feel driven to make a difference in my community and even the world," and "No matter what the odds, if I believe in something, I will make it happen." The effects of MBIs on whistleblowing have not been studied. However, in a variety of populations within and outside of the workplace, mindfulness training has been shown to encourage characteristics similar to the proactive personality style, including autonomy, environmental mastery, purpose in life, clarity about personal values, and willingness to engage in values-consistent behavior in difficult circumstances (Carmody et al. 2009; Flaxman and Bond 2010; Meeten et al. 2015). It therefore seems unlikely that worksite mindfulness training will encourage passive acquiescence with corporate wrongdoing.

Two additional arguments support this position. First claims that nonjudgmental acceptance promotes resignation and helplessness are unfounded. Both MBSR and MBCT provide clear and frequent cautions against this misunderstanding. Kabat-Zinn (2013) states that acceptance "has nothing to do with passive resignation" but rather, "willingness to see things as they are," and an attitude that "sets the stage for acting appropriately in your life, no matter what is happening" (p. 28). The MBCT manual (Segal et al. 2013) makes similar points, noting that nonjudgmental acceptance disrupts maladaptive chains of behavior and facilitates wise decision making in difficult situations. Thus, upon observing unethical behavior in the workplace, an employee with mindfulness skills is likely to recognize and acknowledge the thoughts and feelings that arise (anger, disappointment, worry, etc.), accept them nonjudgmentally as valid responses to the situation, reflect on potential courses of action, and choose valuesconsistent behavior. In contrast, employees without mindfulness training may be more susceptible to denial of what occurred, avoidance of the people involved or those with the power to help, unhelpful emotion-driven behavior such as temper outbursts or excessive drinking, and unproductive rumination about the inadequacies of the work environment or their own failure to address the situation.

Second, the APA ethics code (APA 2010) includes guidelines for psychologists who respond to third-party requests for services and who work with organizations. Psychologists hired by managers to provide training for employees must consider how their services will be used and avoid exposing participants to harm or exploitation. They must communicate clearly with all parties about who is the client, the goals for training, and the limits of confidentiality. A psychologist who realizes that a corporate employer is hoping for increased compliance with unethical practices or oppressive working conditions is required to work toward constructive resolution of this ethical conflict. Although many providers of MBIs are not psychologists, other mental health disciplines have similar ethical principles. 
A recent study raises questions about the effects of an explicitly Buddhist-based approach to worksite mindfulness training on employees' adherence to corporate agendas. Workers' attitudes toward their employers were examined in a study of MAT (Shonin and Van Gordon 2014; Shonin et al. 2014a), an 8-week meditation-based intervention described earlier that teaches Buddhist concepts such as nonself and impermanence. Middle managers in a variety of workplaces reported that MAT helped them to be "less preoccupied with their own agenda and entitlements" and better able to "align their roles with corporate strategy" (Shonin and Van Gordon 2014). Shonin et al. (2014a) suggested that, "via the meditation-induced understanding that there is not a self that exists inherently, independently, or as a permanent entity, employees can begin to dismantle their emphasis on the 'I', the 'me', and the 'mine', and can better synchronize their own interests with those of the organizations" (p. 819). The authors also claimed that their findings may "rebut several established systems of thought within occupational psychology" (p. 820), one of which is the widely endorsed need for organizationdirected work-well-being interventions. That is, rather than addressing problems in the work environment such as inflexible hours, conflicting demands, and poor support infrastructure, the authors suggest that it may be more efficacious to modify employees' "internal (i.e., psychological) working environment" (p. 818) through meditation.

In organizations engaged in ethical practices, the attitudinal shift produced by MAT might be an adaptive outcome. Participants in Shonin et al. reported significant reductions in work-related and general distress and improvements in job satisfaction and performance. In qualitative interviews (Shonin and Van Gordon 2014), they reported that work became an opportunity to flourish and that their understanding of work situations and co-workers' perspectives improved. They also expressed appreciation for their new understanding of nonself and impermanence. However, if acquiescence with unethical or oppressive business practices is a concern, an approach that increases employees' alignment with their employers' agendas might have disadvantages. Although the more secular MBIs described earlier cultivate qualities that may promote whistle-blowing, such as autonomy and clarity about personal values, the effects of this more explicitly Buddhist-based approach on such qualities are unclear.

\section{Deciding What to Teach}

In the early days of psychological research on the efficacy of MBIs, Teasdale et al. (2003) argued that interventions should be based on clear theoretical formulations of how mindfulness can be expected to help with the specific problems to which it is applied. MBCT, for example (Segal et al. 2002), was developed to address a well-documented problem: the tendency for people with a history of depressive episodes to have multiple relapses. An empirically based theory was developed to explain why depression recurs and how recurrences might be prevented. The intervention then was designed to include specific practices and exercises that theory and previous evidence suggested should help participants learn to manage the factors that lead to relapse. Issues of feasibility and acceptability, including participants' willingness to engage with the practices, were carefully considered.

A similar framework may be helpful in considering whether and how ethics should be taught in secular MBIs. A sound theoretical model of how ethics training will address a clearly identified problem or facilitate a desired outcome is essential. In the context of psychological science, theoretical models may draw inspiration from a variety of sources, including spiritual teachings, but must be described in terms with established meanings within psychology and must be testable with psychological research methods. Translation from Buddhism to the language of psychological science can be difficult. As noted in several of the replies to Monteiro et al., Buddhism and psychology have different understandings of many important terms, including suffering (Lindahl 2015) and insight (Purser 2015). Defining such terms in ways that permit scientific study may introduce inconsistencies with the Buddhist teachings.

A clear rationale for how ethics-related training should be conducted in MBIs is also necessary. One option is to allow the cultivation of ethical qualities to remain implicit. In addition to the factors cited earlier in support of this approach, Niemiec (2014) suggested that mindfulness training implicitly encourages virtues discussed in positive psychology: wisdom through the practice of curiosity and the decentered perspective, courage through remaining present with painful thoughts and feelings, humanity by the practice of kindness and compassion, temperance through the practice of self-regulation (of one's attention while practicing and of one's behavior in making time to practice), and transcendence through the understanding of oneself as distinct from one's thoughts and feelings. Empirical work is needed to test these ideas. MBIs also may cultivate awareness of personal values even when explicit values work is not part of the curriculum. Kabat-Zinn (2005) notes that mindfulness facilitates awareness of "the whispered longings" of one's own heart ( $p, 22)$; presumably, these reflect what participants value most deeply.

A second option is to teach ethics as they are described in Buddhist traditions. As noted earlier, several interventions do this, typically through explicit discussion of the eightfold path and the five ethical precepts; some also include teachings about impermanence and nonself. Although a small number of controlled studies support the efficacy of these treatments, they have been compared only to usual care or waiting lists; thus, there is no evidence that MBIs that include explicit 
Buddhist-based ethical training are more effective than those that do not. Several of the replies to Monteiro et al. point out that explicitly Buddhist foundations can be problematic in settings where secular approaches to treatment are required. Although it is common for MBIs to be described as secular adaptations, several authors have raised questions about whether this claim is defensible when consistency with the Buddhist teachings remains an important concern (Purser 2015). Lindahl (2015) suggested that explicit adoption of Buddhist conceptions of ethics and suffering may lead to the perception that MBIs are trying to advance a religious perspective and are therefore inappropriate for some settings.

For researchers and clinicians who prefer to work explicitly with values, virtues, character strengths, or ethical behavior in the workplace, while remaining independent of the Buddhist teachings, empirically based psychological approaches appear promising. Many MBIs incorporate values work without reference to or reliance on Buddhist ethics. Hayes (2002) notes that ACT and Buddhist teachings have several clear parallels but states that he made no attempt to base ACT on Buddhism and that the parallels are an "unexpected confluence" showing that both are working with "topics central to human suffering" (p. 58). The virtues and character strengths of positive psychology were derived from the study of religious and philosophical traditions, including Buddhism, but have been conceptualized in ways that intentionally embrace the language and methods of contemporary psychological science. Organizational psychology and related disciplines (occupational psychology, personnel psychology, business ethics) provide additional bodies of research on factors related to ethical behavior in the workplace.

\section{Conclusions}

Discussion of explicit ethical training in MBIs raises questions about the source of authority regarding what is ethical. Codes of professional ethics that require respect for cultural diversity and self-determination (e.g., APA 2010) make it problematic for mental health and other professionals to teach ethics based on a particular religious or spiritual framework in many contemporary secular settings. Methods based on self-identified values or cross-culturally recognized virtues and character strengths appear to have several advantages over the explicitly Buddhist-based approaches to ethics training described earlier. They have stronger theoretical and empirical foundations in psychological science, can be used in a variety of secular settings, and are appropriate for a wide range of clients, regardless of their religious or spiritual orientations.

Buddhism is a rich tradition that has informed several MBIs that now have strong empirical support for their efficacy. It may be tempting to assume that MBIs would be even more effective if they were more consistent with the Buddhist teachings; however, this is an untested proposition. It is possible that the efficacy of MBIs in Western settings is attributable, at least in part, to adaptations that have made them less consistent with the Buddhist teachings. The most important question facing MBIs is not whether we can make them more consistent with Buddhism but how we can maximize their benefits for the broadest possible spectrum of participants. When sound theory and empirical findings suggest that explicit work with ethics, values, virtues, or character strengths may accomplish this, we should test these hypotheses using the best available methods of psychological science and with openness to where the findings may lead us.

Acknowledgments I thank Alex Brake, Melody Carswell, Jessica Peters, and Richard Smith for helpful comments on earlier drafts.

\section{Compliance with Ethical Standards}

Conflict of Interest The authors declare that they have no conflict of interest.

\section{References}

Amaro, A. (2015). A holistic mindfulness. Mindfulness, 6, 63-73. American Psychological Assocation. (2010). Ethical principles of psychologists and code of conduct. American Psychologist, 65, 493.

Avants, S. K., Beitel, M., \& Margolin, A. (2005). Making the shift from 'addict self' to 'spiritual self': Results from a Stage I study of Spiritual Self-Schema (3-S) therapy for the treatment of addiction and HIV risk behavior. Mental Health, Religion, \& Culture, 8, 167177.

Avants, S. K., \& Margolin, A. (2004). Development of spiritual selfschema (3-S) therapy for the treatment of addictive and HIV risk behavior: a convergence of cognitive and Buddhist psychology. Journal of Psychotherapy Integration, 14, 253-289.

Baer, R. A. \& Lykins, E. L. B. (2011). Mindfulness and positive psychological functioning. In K. Sheldon, T. Kashdan, \& M. Steger (Eds.), Designing the future of positive psychology: Taking stock and moving forward (pp. 335-348). NY: Oxford University Press.

Bateman, T., \& Crant, J. (1993). The proactive component of organizational behavior: a measure and correlates. Journal of Organizational Behavior, 14, 103-118.

Baumeister, R., Matthew, G., DeWall, C., \& Oaten, M. (2006). Selfregulation and personality: how interventions increase regulatory success, and how depletion moderates the effects of traits on behavior. Journal of Personality, 74, 1773-1802.

Bennett, W. J. (1993). The book of virtues. New York: Simon \& Schuster. The Bhagavadgita (N. V. Thadani, Trans.). (1990). New Delhi, India: Munshiram Manoharlal.

Birnie, K., Speca, M., \& Carlson, L. D. (2010). Exploring selfcompassion and empathy in the context of mindfulness-based stress reduction (MBSR). Stress and Health, 26, 359-371.

Bishop, S. R., Lau, M., Shapiro, S., Carlson, L., Anderson, N. C., Carmody, J., et al. (2004). Mindfulness: a proposed operational definition. Clinical Psychology: Science and Practice, 11, 230-241.

Bond, F. W. (2004). Getting the balance right: the need for a comprehensive approach to occupational health. Work and Stress, 18, 146-148.

Bowen, S., Chawla, N., \& Marlatt, A. (2011). Mindfulness-based relapse prevention for addictive behaviors: a clinician's guide. NY: Guilford. 
Boy Scouts of America. (1998). Boy Scout Handbook (11 th ed.). Irving, TX: Author.

Branstetter-Rost, A., Cushing, C., \& Douleh, T. (2009). Personal values and pain tolerance: does a values intervention add to acceptance? The Journal of Pain, 10, 887-892.

Briscoe, C. (2014). A study investigating the effectiveness of mindfulness-based strengths practice. Unpublished data.

Carmody, J., Baer, R., Lykins, E., \& Olendzki, N. (2009). An empirical study of the mechanisms of mindfulness in a mindfulness-based stress reduction program. Journal of Clinical Psychology, 65, 613626.

Cayoun, B. A. (2011). Mindfulness-integrated CBT: principles and practice. Chichester, UK: John Wiley \& Sons.

Cohen, G. L., \& Sherman, D. K. (2014). The psychology of change: selfaffirmation and social psychological intervention. Annual Review of Psychology, 65, 333-371.

Condon, P., Desbordes, G., Miller, W., \& Desteno, D. (2013). Meditation increased compassionate responses to suffering. Psychological Science, 24, 2125-2127.

Creswell, J. D., Welch, W. T., Taylor, S. E., Sherman, D. K., Gruenewald, T. L., \& Mann, T. (2005). Affirmation of personal values buffers neuroendocrine and psychological stress responses. Psychological Science, 16, 846-851.

Crocker, J., Niiya, Y., \& Mischkowski, D. (2008). Why does writing about important values reduce defensiveness? Self-affirmation and the role of positive other-directed feelings. Psychological Science, 19, 740-747.

Dahlsgaard, K., Peterson, C., \& Seligman, M. E. P. (2005). Shared virture: The convergence of valued human strengths across culture and history. Review of General Psychology, 9, 203-213.

Davis, J. H. (2015). Facing up to the question of ethics in mindfulnessbased intervention. Mindfulness, 6, 46-48.

Emmons, R. A., \& Mishra, A. (2011). Why gratitude enhances wellbeing: what we know, what we need to know. In K. M. Sheldon, T. B. Kashdan, \& M. F. Steger (Eds.), Designing positive psychology: taking stock and moving forward (pp. 248-262). NY: Oxford University Press.

Flaxman, P., \& Bond, F. (2006). Acceptance and commitment therapy (ACT) in the workplace. In R. A. Baer (Ed.), Mindfulness-based treatment approaches: clinician's guide to evidence base and applications (pp. 377-402). San Diego: Elsevier.

Flaxman, P., \& Bond, F. (2010). Acceptance and commitment training: promoting psychological flexibility in the workplace. In R. A. Baer (Ed.), Assessing mindfulness and acceptance processes in clients: illuminating the theory and practice of change (pp. 281-306). Oakland, CA: New Harbinger.

Flaxman, P., Bond, F., \& Livheim, F. (2013). The mindful and effective employee: an acceptance and commitment therapy training manual for improving well-being and performance. Oakland, CA: New Harbinger.

Fleming, J. E., \& Kocovski, N. L. (2013). The mindfulness and acceptance workbook for social anxiety and shyness. Oakland, CA: New Harbinger.

Franklin, B. (1961). The autobiography. In L. J. Lemisch (Ed.), The autobiography and other writings (pp. 15-180). New York: Signet Classic (Original work published ca. 1790).

Ganster, D., Mayes, B., Sime, W., \& Tharpe, G. (1982). Managing occupational stress: a field experiment. Journal of Applied Psychology, 67, 533-542.

Germer, K., Siegel, R., \& Fulton, P. (Eds.). (2005). Mindfulness and psychotherapy. NY: Guilford.

Gillet, N., Lafreniere, M., Vallerand, R., Huart, I., \& Fouquereau, E. (2014). The effects of autonomous and controlled regulation of performance-approach goals on well-being: a process model. British Journal of Social Psychology, 53, 154-174.
Greenberg, M. T., \& Mitra, J. L. (2015). From mindfulness to right mindfulness: the intersection of awareness and ethics. Mindfulness, 6, 74 78.

Grossman, P. (2015). Mindfulness: awareness informed by an embodied ethic. Mindfulness, 6, 17-22.

Harackiewicz, J., Canning, E., Tibbetts, Y., Giffen, C., \& Hyde, J. (2014). Closing the social class achievement gap for first generation students in undergraduate biology. Journal of Educational Psychology, 106, $375-389$.

Hayes, S. C. (2002). Buddhism and acceptance and commitment therapy. Cognitive and Behavioral Practice, 9, 58-66.

Hayes, S. C., Strosahl, K. D., \& Wilson, K. G. (1999). Acceptance and commitment therapy: an experiential approach to behavior change. NY: Guilford.

Hayes, S. C., Luoma, J. B., Bond, F. W., Masuda, A., \& Lillis, J. (2006). Acceptance and commitment therapy: model, processes, and outcomes. Behaviour Research and Therapy, 44, 1-25.

Hayes, S. C., Strosahl, K. D., \& Wilson, K. G. (2012). Acceptance and commitment therapy: the process and practice of mindful change (2nd ed.). NY: Guilford.

Hofmann, S. G., Grossman, P., \& Hinton, D. E. (2011). Loving-kindness and compassion meditation: potential for psychological interventions. Clinical Psychology Review, 31, 1126-1132.

Irving, J., Dobkin, P., \& Park, J. (2009). Cultivating mindfulness in health care professionals: a review of empirical studies of mindfulnessbased stress reduction (MBSR). Complementary Therapies in Clinical Practice, 15, 61-66.

Jennings, P., Snowberg, K., Coccia, M., \& Greeberg, M. (2011). Improving classroom learning environments by cultivating awareness and resilience in education (CARE): results of two pilot studies. Journal of Classroom Interaction, 46, 37-48.

Jennings, P., Snowberg, K., Frank, J., Coccia, M., \& Greenberg, M. T. (2013). Improving classroom learning environments by cultivating awareness and resilience in education (CARE): results of a randomized controlled trial. School Psychology Quarterly, 28, 374-390.

Kabat-Zinn, J. (1994). Wherever you go, there you are: mindfulness meditation in everyday life. NY: Hyperion.

Kabat-Zinn, J. (2003). Mindfulness-based interventions in context: past, present and future. Clinical Psychology: Science and Practice, 10, $144-156$.

Kabat-Zinn, J. (2005). Coming to our senses: healing ourselves and the world through mindfulness. NY: Hyperion.

Kabat-Zinn, J. (2011). Some reflections on the origins of MBSR, skillful means, and the trouble with maps. Contemporary Buddhism, 12, 281-306.

Kabat-Zinn, J. (2013). Full catastrophe living: using the wisdom of your body and mind to face stress, pain, and illness (2nd ed.). NY: Bantam Books.

Keng, S., Smoski, M. J., Robins, C. J., Ekblad, A. G., \& Brantley, J. G. (2012). Mechanisms of change in mindfulness-based stress reduction: self-compassion and mindfulness as mediators of intervention outcomes. Journal of Cognitive Psychotherapy, 26, 270-280.

Kristeller, J., Wolever, R., \& Sheets, V. (2014). Mindfulness-based eating awareness training (MB-EAT) for binge eating: a randomized clinical trial. Mindfulness, 5, 282-297.

Kuyken, W., Watkins, E., Holden, E., White, K., Taylor, R., Byford, S., et al. (2010). How does mindfulness-based cognitive therapy work? Behaviour Research and Therapy, 48, 1105-1112.

Legault, L., Al-Khindi, T., \& Inzlicht, M. (2012). Preserving integrity in the face of performance threat: self-affirmation enhances neurophysiological responsiveness to errors. Psychological Science, 23, 14551460.

Levin, M., Hildebrandt, M., Lillis, J., \& Hayes, S. C. (2012). The impact of treatment components suggested by the psychological flexibility model: A meta-analysis of laboratory-based component studies. Behavior Therapy, 43, 741-756. 
Lindahl, J. (2015). Why right mindfulness may not be right for mindfulness. Mindfulness, 6, 57-62.

Linehan, M. M. (1993). Cognitive-behavioral treatment of borderline personality disorder. NY: Guilford.

Linehan, M. M. (2015). DBT skill training manual (2nd ed.). NY: Guilford.

Lounsbury, J. W., Fisher, L. A., Levy, J. J., \& Welsh, D. P. (2009). An investigation of character strengths in relation to the academic success of college students. Individual Differences Research, 7, 52-69.

Margolin, A., Beitel, M., Schuman-Olivier, Z., \& Avants, S. K. (2006). A controlled study of a spirituality-focused intervention for increasing motivation for HIV prevention among drug users. Aids Education and Prevention, 18, 311-322.

Margolin, A., Schuman-Olivier, Z., Beitel, M., Arnold, R., Fulwiler, C., \& Avants, S. (2007). A preliminary study of spiritual self-schema (3$\mathrm{S}^{+}$) therapy for reducing impulsivity in HIV-positive drug users. Journal of Clinical Psychology, 63, 979-999.

Marlatt, G. A., \& Kristeller, J. L. (1999). Mindfulness and meditation. In W. R. Miller (Ed.), Integrating spirituality into treatment (pp. 67 84). Washington DC: American Psychological Association.

McCullough, M., Kimeldorf, M., \& Cohen, A. (2008). An adaptation for altruism? The social causes, social effects, and social evolution of gratitude. Current Directions in Psychology Science, 17, 281-285.

Meeten, F., Whiting, S., \& Williams, C. (2015). An exploratory study of group mindfulness-based cognitive therapy for older people with depression. Mindfulness, 6, 467-474.

Miceli, M., \& Near, J. (2005). Standing up or standing by: what predicts blowing the whistle on organizational wrongdoing? Research in Personnel and Human Resources Management, 24, 95-136.

Miceli, M., Near, J., Rehg, M., \& Van Scotter, J. (2012). Predicting employee reactions to perceived organizational wrongdoing: demoralization, justice, proactive personality, and whistle-blowing. Human Relations, 65, 932-954.

Monteiro, L., \& Musten, F. (2013). Mindfulness starts here: an eightweek guide to skillful living. Victoria, Canada: Friesen Press.

Monteiro, L., Nuttall, S., \& Musten, F. (2010). Five skillful habits: an ethics-based mindfulness intervention. Counseling et Spiritualité, 29, 91-104.

Monteiro, L. M., Musten, R. F., \& Compson, J. (2015). Traditional and contemporary mindfulness: finding the middle path in the tangle of concerns. Mindfulness, 6, 1-13.

Murphy, L. (1984). Occupational stress management; A review and appraisal. Journal of Occupational Psychology, 57, 1-15.

Niemiec, R. (2013). VIA character strengths: research and practice (The first 10 years). In H. H. Knoop \& A. Delle Fave (Eds.), Well-being and cultures: perspectives on positive psychology (pp. 11-30). NY: Springer.

Niemiec, R. (2014). Mindfulness and character strengths: a practical guide to flourishing. Boston, MA: Hogrefe.

Niemiec, R., \& Lissing, J. (2015). Mindfulness-based strengths practice (MBSP) for enhancing well-being, managing problems, and boosting positive relationships. In I. Ivtzan \& T. Lomas (Eds.), Mindfulness in positive psychology: the science of meditation and well-being. London: Routledge.

Park, N., \& Peterson, C. (2006). Methodological issues in positive psychology and the assessment of character strengths. In A. D. Ong \& M. van Dulmen (Eds.), Handbook of methods in positive psychology (pp. 292-305). NY: Oxford University Press.

Park, N., Peterson, C., \& Seligman, M. (2004). Strengths of character and well-being. Journal of Social and Clinical Psychology, 23, 603619

Peterson, C. (2006). A primer in positive psychology. NY: Oxford University Press

Peterson, C., \& Park, N. (2011). Character strengths and virtues: their role in well-being. In S. Donaldson, M. Csikszentmihalyi, \& J.
Nakamura (Eds.), Applied positive psychology: improving everyday life, health, schools, work, and society. NY: Psychology Press.

Peterson, C., Park, N., \& Seligman, M. (2005). Assessment of character strengths. In G. P. Koocher, J. C. Norcross, \& S. S. Hill III (Eds.), Psychologists' desk reference (2nd ed., pp. 93-98). NY: Oxford University Press.

Peterson, C., Park, N., \& Seligman, M. (2006). Greater strengths of character and recovery from illness. Journal of Positive Psychology, 1, $17-26$.

Peterson, C. \& Seligman, M. E. P. (2004). Character strengths and virtues: A handbook and classification. NY: Oxford University Press.

Proyer, R., Gander, F., Wellenzohn, S., \& Ruch, W. (2014). Positive psychology interventions in people aged 50-79 years: long-term effects of placebo-controlled online interventions on well-being and depression. Aging and Mental Health, 18, 997-1005.

Purser, R. E. (2015). Clearing the muddled path of traditional and contemporary mindfulness: a response to Monteiro, Musten, and Compson. Mindfulness, 6, 23-45.

Roemer, L., Orsillo, S. M., \& Salters-Pednault, K. (2008). Efficacy of an acceptance-based behavior therapy for generalized anxiety disorder: Evaluation in a randomized controlled trial. Journal of Consulting and Clinical Psychology, 76, 1083-1089.

Ruiz, F. J. (2010). A review of acceptance and commitment therapy (ACT) empirical evidence: correlational, experimental psychopathology, component and outcome studies. International Journal of Psychology and Psychological Therapy, 10, 125-162.

Ryan, R. M., \& Deci, E. L. (2000). Self-determination theory and the facilitation of intrinsic motivation, social development, and wellbeing. American Psychologist, 55, 68-78.

Ryff, C. D. (1989). Happiness is everything, or is it? Explorations on the meaning of psychological wellbeing. Journal of Personality and Social Psychology, 57, 1069-1081.

Schwartz, S. H., \& Bilsky. (1987). Toward a psychological structure of human values. Journal of Personality and Social Psychology, 53, $550-562$.

Schwartz, S. H., \& Bilsky, W. (1990). Toward a theory of universal content and structure of values: extensions and cross-cultural replications. Journal of Personality and Social Psychology, 58, 878-891.

Scott, G., Leritz, L., \& Mumford, M. (2004). The effectiveness of creativity training: a quantitative review. Creativity Research Journal, $16,361-388$.

Segal, Z. V., Williams, J. M. G., \& Teasdale, J. D. (2002). Mindfulnessbased cognitive therapy for depression: A new approach to preventing relapse. NY: Guilford.

Segal, Z. V., Williams, J. M. G., \& Teasdale, J. D. (2013). Mindfulnessbased cognitive therapy for depression: a new approach to preventing relapse (2nd ed.). New York: Guilford.

Seligman, M., Steen, T., Park, N., \& Peterson, C. (2005). Positive psychology progress: empirical validation of interventions. American Psychologist, 60, 410-421.

Shapiro, S., Schwartz, G. E., \& Bonner, G. (1998). Effects of mindfulness-based stress reduction on medical and premedical students. Journal of Behavioral Medicine, 21, 581-599.

Sheldon, K. M. (2002). The self-concordance model of healthy goal striving: when personal goals correctly represent the person. In E. Deci \& R. Ryan (Eds.), Handbook of self-determination research (pp. 65-86). Rochester, NY: University of Rochester Press.

Sheldon, K., \& Elliott, A. (1999). Goal striving, need satisfaction, and longitudinal well-being: the self-concordance model. Journal of Personality and Social Psychology, 76, 482-497.

Sherman, D., Nelson, L., \& Steele, C. (2000). Do messages about health risks threaten the self? Increasing the acceptance of threatening health messages via self-affirmation. Personality and Social Psychology Bulletin, 26, 1046-1058. 
Shonin, E. \& Van Gordon, W. (2014). Managers' experiences of Meditation Awareness Training. Mindfulness. doi:10.1007/s12671014-0334-y.

Shonin, E., Van Gordon, W., Dunn, T., Singh, N., \& Griffiths, M. (2014a). Meditation awareness training (MAT) for work-related wellbeing and job performance: a randomized controlled trial. International Journal of Mental Health and Addiction, 12, 806-823.

Shonin, E., Van Gordon, W., \& Griffiths, M. (2014b). The treatment of workaholism with meditation awareness training: a case study. Explore, 10, 193-195.

Shonin, E., Van Gordon, W., \& Griffiths, M. (2014c). Cognitive behavioral therapy (CBT) and meditation awareness training (MAT) for the treatment of co-occurring schizophrenia and pathological gambling: a case study. International Journal of Mental Health and Addiction, 12, 181-196.

Shonin, E., Van Gordon, W., \& Griffiths, M. (2014d). Meditation awareness training (MAT) for improved psychological well-being: a qualitative examination of participants' experiences. Journal of Religion and Health, 53, 849-863.

Steele, C. M. (1999). The psychology of self-affirmation: sustaining the integrity of the self. In R. F. Baumeister (Ed.), The self in social psychology (pp. 372-390). NY: Psychology Press.

Teasdale, J. D., Segal, Z. V., \& Williams, J. M. G. (2003). Mindfulness training and problem formulation. Clinical Psychology: Science and Practice, 10, 157-160.

Turner, S. E. (Ed.). (1880). Einhard: the life of Charlemagne. New York: Harper \& Brothers.
Vadera, A., Aguilera, R., \& Caza, B. (2009). Making sense of whistle-blowing's antecedents: learning from research on identity and ethics programs. Business Ethics Quarterly, 19, $553-586$.

Van Gordon, W., Shonin, E., Sumich, A., Sundin, E., \& Griffiths, M. D. (2014). Meditation awareness training (MAT) for psychological well-being in a sub-clinical sample of university students: a controlled pilot study. Mindfulness, 5, 381-391.

Wade, N., Hoyt, W., Kidwell, J., \& Worthington, E. (2014). Efficacy of psychotherapeutic interventions to promote forgiveness: a metaanalysis. Journal of Consulting and Clinical Psychology, 82, 154170.

Williams, J. M. G., \& Kabat-Zinn, J. (Eds.). (2013). Mindfulness: diverse perspectives on its meaning, origins and applications. London: Routledge.

Wilson, K. G., \& DuFrene, T. (2008). Mindfulness for two: an acceptance and commitment therapy approach to mindfulness in psychotherapy. Oakland, CA: New Harbinger.

Wilson, K., Sandoz, E., Flynn, M., Slater, R., \& DuFrene, T. (2010). Understanding, assessing, and treating values processes in mindfulness- and acceptance-based therapies. In R. A. Baer (Ed.), Assessing mindfulness and acceptance processes in clients (pp. 77106). Oakland, CA: New Harbinger.

Wolever, R., Bobinet, K., McCabe, K., Mackenzie, E., Fekete, E., Kusnick, C., \& Baime, M. (2012). Effective and viable mind-bpdy stress reduction in the workplace: a randomized controlled trial. Journal of Occupational Health Psychology, 17, 246-258. 